\title{
Decade Wise Analysis of Ankle Plantar Flexors Strength in Adults Using One Leg Heel Raise Test (OLHR)
}

\author{
Dr. Priya Chitre ${ }^{1}$, Dr. Sejal Prabhu ${ }^{2}$ \\ ${ }^{I}$ Associate Professor, Department of Neurophysiotherapy, MAEER'S Physiotherapy College, India \\ ${ }^{2}$ Sancheti Institute College of Physiotherapy, Pune, India
}

\begin{abstract}
One Leg Heel raise test is used extensively in clinical practice to assess the strength of ankle plantar flexors. Though it has good reliability and face validity, there is dearth of evidence for definitive normative values in different decades. Our study assessed 40 subjects each in different decades between 20 to 70 years divided in 5 groups, with a total of 200 subjects, for number of repetitions of one leg heel raise. It was seen that the mean number of repetitions in the decade of 20 to 30 was 32 repetitions and thereafter it reduced gradually, with only an average of 7 repetitions being performed between the decades of 60 to 70 years. The difference in average number of heel raises being performed every decade was statistically significant. This could be attributed to age related changes in neuromuscular morphology. Further research is needed to increase the sample size and find normative values of OLHR for different decades.
\end{abstract}

Keywords - Ankle plantar flexors, Calf raise, Decade wise, one leg heel raise

\section{Introduction}

Ankle plantar flexor strength has important role in stability and mobility of both knee joint and ankle joint. They control the forward displacement of tibia over the talus during stance phase, help in initiation of swing phase and assist in reducing energy consumption during gait cycle by minimizing the vertical displacement of center of gravity. [1]

It is crucial to assess ankle plantar flexor strength, as their weakness results in difficulties in walking and impaired standing balance [1-3]. There are various methods to assess muscle strength, such as manual muscle testing (MMT), $[4,5]$ tests using handheld dynamometers, [6,7] and isokinetic testing. [8,9] Clinically, MMT is more frequently used than the other methods due to its convenience and low cost. [4, 5] In spite of its subjective variations, it is the most popular clinical method to identify muscle weakness.

MMT assesses muscle strength by the muscle's ability to contract against gravity alone or gravity along with examiner's resistance. $[4,5]$ Checking ankle plantar flexors strength in the prone against the examiner's strength is considered inadequate as they work primarily during daily activities against full body weight.[8]

A modified technique, therefore, has been proposed using the repeated One-Leg Heel-Rise (OLHR) test. $[4,5]$ This is the preferred method of testing the strength of the ankle plantarflexors in the clinical setting. According to a study done by Lunford BR et al, the ability of a person to perform 25 or more repetitions of oneleg heel-rise in a standing position without loss of balance or showing fatigue is considered to indicate "normal" strength of the plantar flexors, regardless of the individual's age or sex or the activity level.[6] Kendall proposes the ability of a person to perform 20 or more repetitions of one-leg heel-rise in a standing position without loss of balance or showing fatigue to indicate "normal" strength of the plantar flexors, regardless of the individual's age or sex or the activity level. $[4,5]$

In a systematic review done by Kim Hébert-Losiera et al on parameters of Calf raise test, it was found that most studies gave an average value of 27 repetitions in healthy adults and 19 repetitions in pathological subjects. [12] However, this normative grading method does not take into consideration the age of the subject. There is a possibility that the normative values may not be same for all the ages owing to degenerative changes in the muscle tissue and reduced function in normal subjects as well.

Therefore, we have conducted this study to determine the average number of repetitions of OLHR that can be performed by adult subjects of every decade of age ( 20 years -70 years) and whether there is a significant change in every decade.

Our Null hypothesis was that there will be no change in the average number of repetitions of OLHR performed per decade from 20 to 70 and our experimental hypothesis was that there will be a reduction in the average number of repetitions of OLHR performed every decade from 20 to 70 years. 
Study Design: Cross Sectional

\section{Methodology}

Sample size: 200 with 40 subjects in 5 groups.

A Total of 200 subjects, with 40 subjects in each decade between 20-30,31-40,41-50, 51-60, 61-70 with normal gait pattern, with BMI between 19 to 24, without lower limb joint pain or injury were selected. Whereas, subjects with lower limb injuries, those having cardio pulmonary diseases, those involved in regular exercise or athletic training were excluded. They were allotted to 5 groups according the age decade they belonged to.

The subjects were demonstrated one leg heel raises (OLHR) by the therapist and told to perform the same up to the maximum excursion possible by them. The subjects performed OLHR test only once and the maximum number of repetitions was noted as the final reading. They were allowed to take the support of a wall with one finger, if needed, while performing the task. Each OLHR was completed with the first second spent in raising the heel up and the following second spent in lowering the heel down while keeping the knee in extension. A metronome was used to set the beat corresponding to the rhythm of the heel rise.

The participant was encouraged to try his best until one of the following occurred.

1. The participant could not perform any further OLHR (fatigue).

2. The plantar flexion angle reduced to less than $50 \%-75 \%$ of the initial angle.

3. The participant rocked back and forth or lost balance.

4. The knee joint of the testing extremity flexed.

\section{Results}

Subjects performed the test only once and maximum numbers of repetitions were noted down for each age group. The average of number of repetitions performed for each decade was noted along with its standard deviation. One way Anova applied between the groups gave an f value of 57.40 and a $\mathrm{p}$ value of 0.000 , which signifies that the differences observed within groups are statistically significant. Mann-Whitney rank sum test was applied between 2 consecutive decades and it was seen that the difference in average repetitions between decade 20-30 and 30-40, as well as decade 40-50 and 50-60, was not statistically significant ( $\mathrm{p}=0.223)$ and $(\mathrm{p}=0.093)$ respectively. However, the difference in average number of repetitions between decades $30-40$ and 40-50 as well as between 50-60 and 60-70 were statistically significant $(\mathrm{p}=0.000)$

Table 1: Average number of repetitions of OLHR in each group with mean and standard deviation

\begin{tabular}{|l|l|}
\hline Age Group (decades) & $\begin{array}{l}\text { Average number of repetitions of OLHR } \\
\text { with standard deviation }\end{array}$ \\
\hline 20 to 30 & $31.85 \pm 9.09(20-50)$ \\
\hline 31 to 40 & $27.95 \pm 5.45(20-36)$ \\
\hline 41 to 50 & $17.65 \pm 5.24(10-26)$ \\
\hline 51 to 60 & $14.5 \pm 5.31(6-23)$ \\
\hline 61 to 70 & $6.9 \pm 3.25(2-12)$ \\
\hline
\end{tabular}

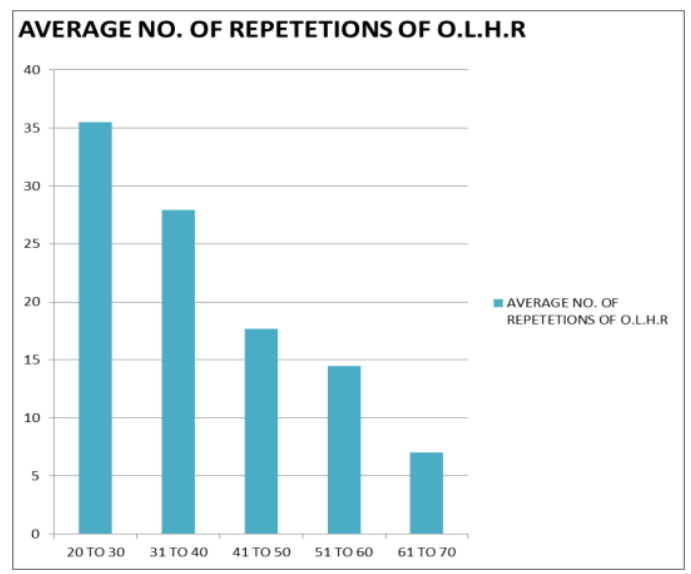

Graph 1: Average number of repetitions of one leg heel raise in different decades.

It was observed that age group of 20 - 30 years had maximum number of repetitions with the mean of 32 repetitions. It was found that numbers of repetitions were progressively decreased with the advancing age of the subjects. The lowest number of repetitions was observed in age group of 61-70 years with the mean being 7 
repetitions only. The differences between every decade were also found to be statistically significant as seen by the One way Anova $(\mathrm{p}<0.0001)$

\section{Discussion}

It was observed from this study, that the ability to perform OLHR progressively decreased with increase in age. The average number of repetitions of one leg heel raise was 32 in the decade of 20-30 years and 28 in the decade of 30- 40 years. This difference was not statistically significant. This is consistent with findings of studies done by Karsten Keller et al and Zatsiorsky VM et al that state that physical capacity is highest between the age of 20 to 30 years and reported loss of muscle mass and capacity is low upto the age of 40 years. $[13,14]$

From the decade of 40 to 50 years repetitions of OLHR decreased to a mean of 18 . According to a study done by Descehnes MR, [15], beyond the age of 45 to 50, there is an increased incidence of sarcopenia i.e. loss of muscle mass. This can be attributed to the age related changes that occur in the structure and function of muscle fibers such as shrinkage of muscle fibers, decrease in the number of the muscle fibers, reduction in the number of functional motor neurons and slowing of the reaction rate.

During the decade of 60 to 70 years the mean repetitions of one leg heel raise possible were only 7 . It has been proposed that in the elderly the rate of loss of muscle mass and strength is accelerated due to a decrease in the production of anabolic hormones such as testosterone, growth hormone and insulin-like growth factor-1 which impairs the capacity of skeletal muscle to incorporate amino acids and synthesise proteins. Also, an increase in the release of catabolic agents, especially interleukin-6, increases the rate of muscle wasting among the elderly. [16-20]

\section{Conclusion}

This study concludes that as the age increases, the average number of repetitions of one leg heel raises decreases decade-wise and the difference is significant between the decades of 31-40 and 41- 50 as well as between decades of 51- 60 and 61-70.

Thus, the ability to perform OLHR decreases with advancing age with the mean repetitions of calf raises being performed in the decade of 20-30 being 32, between 31-40 being 28, between 41-50 being 18 , between 51-60 being 15 and between 61-70 being 7 .

\section{Scope of Study}

This study can be repeated with a larger sample size covering more decades. Gender differences in performing OLHR can be studied. An electrogoniometer can be applied to the ankle to record accurate ankle ranges. The results of the study can then be applied in clinical practice to consider different norms for calf raises in different age groups.

\section{References}

[1]. Sutherland DH, Cooper L, Daniel D, The role of the ankle plantar flexors in normal walking, J Bone Joint Surg Am.1980;62:354363.

[2]. Horak FB, Henry SM, Shumway-Cook A, Postural perturbations: new insights for treatment of balance disorders, Phys Ther.1997 ;77:517-533.

[3]. Meinders M, Gitter A, Czerniecki JM, The role of ankle plantar flexor muscle work during walking, Scand J Rehabil Med.1998 ;30:39-46.

[4]. Hislop HJ, Montgomery J. Daniels and Worthingham's Muscle Testing: Techniques of Manual Examination. 6th ed. Philadelphia, Pa: WB Saunders Co;1995.

[5]. Florence Kendall, Muscles-testing and function, with posture and Pain, Ed. 5, Lipincott William and William, 2005

[6]. Lunsford BR, Perry J. The standing heel-rise test for ankle plantar flexion: criterion for normal, Phys Ther 1995; 75(8):694-8.

[7]. Krishnan R, Sear M, Harrold J, Nielsen DH. Intrarater reliability of manual muscle testing and hand-held dynametric muscle testing. Phys Ther. 1987;67:1342-7

[8]. Lin $\mathrm{CH}, \mathrm{Hu} \mathrm{MH}$, Cheng SC, Tsauo JY. Validity and reliability of hand-held dynamometer in measuring strength of the lower extremity muscles, Formosan Journal of Physical Therapy.2000;25:41-7

[9]. Bohannon RW. Alternatives for measuring knee extension strength of the elderly at home. Clin Rehabil.1998;12:434-440

[10]. Svantesson U, Österberg U, Thomee R, et al. Muscle fatigue in a standing heel-rise test. Scand J Rehabil Med 1998; 30(2):67-72

[11]. Kahn M, Williams G. Clinical tests of ankle plantarflexor strength do not predict ankle power generation during walking; Am J Phys Med Rehabil. 2015 Feb;94(2):114-22

[12]. Hébert-Losier K1, Newsham-West RJ, Schneiders AG, Sullivan SJ, Raising the standards of the calf-raise test: a systematic review, J Sci Med Sport. 2009 Nov;12(6):594-602

[13]. Karsten Keller and Martin Engelhardt, Strength and muscle mass loss with aging process. Age and strength loss, Muscles Ligaments Tendons J. 2013 Oct-Dec; 3(4): 346-350

[14]. Zatsiorsky VM, Kreamer WJ. Krafttraining in praxis und wissenschaft. Aachen: Meyer \& Meyer Verlag; 2008

[15]. Deschenes MR, Effects of aging on muscle fibre type and size, Sports Med. 2004;34(12):809-24

[16]. Jan M-H, Chai H-M, Lin Y-F, et al. Effects of age and sex on the results of an ankle plantar-flexor manual muscle test. Phys Ther 2005; 85(10):1078-84

[17]. Sunnerhagen KS, Hedberg M, Henning G-B, et al. Muscle performance in an urban population sample of 40- to 79-year-old men and women. Scand J Rehabil Med 2000; 32(4):159-67 
[18]. Wu G. The relation between age-related changes in neuromusculoskeletal system and dynamic postural responses to balance disturbance. J Gerontol A Biol Sci Med Sci. 1998;53:M320-6

[19]. Bok SK, Lee TH, Lee SS. The effects of changes of ankle strength and range of motion according to aging on balance. Ann Rehabil Med. 2013;37:10-6

[20]. Amundsen LR. Effects of age on joints and ligaments. In: Kauffman TL, editor. Geriatric rehabilitation manual. New York: Churchill Livingstone; 1999. pp. 14-16

[21]. Laughton CA, Slavin M, Katdare K, Nolan L, Bean JF, Kerrigan DC, et al. Aging, muscle activity, and balance control: physiologic changes associated with balance impairment. Gait \& posture. $2003 ; 18: 101-8$ 